\title{
Lm-LLO immunotherapies targeting multiple antigens and their impact on different mechanisms in the tumor microenvironment
}

\author{
Anu Wallecha*, Poonam Molli \\ From Society for Immunotherapy of Cancer 29th Annual Meeting \\ National Harbor, MD, USA. 6-9 November 2014
}

Overexpression of tumor associated antigens (TAA) such as carbonic anhydrase 9 (CA9), HER2/neu and high molecular weight melanoma associated antigen (HMW-MAA) is associated with aggressive high-grade tumors leading to disease progression and reduced survival. CA9 is a cell surface enzyme that catalyzes the reversible hydration of carbon dioxide to bicarbonate and is overexpressed in response to tumor hypoxia in many common tumor types. CA9 plays a critical role in hypoxia-associated tumor acidosis, which plays an important role in tumor progression and chemoresistance in various types of cancer. Current HER2/neu-directed therapies confer limited clinical benefits and most patients experience progressive disease indicating that additional therapeutic strategies targeting HER2/neu could have potential. HMW-MAA is reported to be a TAA as well as an angiogenesis associated protein, as it is expressed at high levels by activated pericytes and pericytes in tumor angiogenic vasculature that are associated with neovascularization in vivo. We hypothesized that an $L m$-LLO immunotherapy, using attenuated Listeria moncytogenes $(\mathrm{Lm})$-LLO as the vector capable of delivering multiple antigens would likely have a synergistic effect on decreasing tumor growth by targeting independent mechanisms that support tumor growth. We created two bivalent $L m$-LLO immunotherapies expressing two antigens such as HER2/HMW-MAA or HER2/CA9. These bivalent $L m$-LLO immunotherapies efficiently secreted two antigens, grew intracellularly and escaped the phagolysosome, supporting that recombinant bacteria retained their ability to deliver antigen successfully in an antigen presenting cell. Preliminary antitumor therapeutic studies in the treatment of mice bearing established tumors expressing HER2 demonstrate that both of these

Advaxis, Inc, Princeton, NJ, USA
Cite this article as: Wallecha and Molli: Lm-LLO immunotherapies targeting multiple antigens and their impact on different mechanisms in the tumor microenvironment. Journal for ImmunoTherapy of Cancer 2014 2(Suppl 3):P63.

Submit your next manuscript to BioMed Central and take full advantage of:

- Convenient online submission

- Thorough peer review

- No space constraints or color figure charges

- Immediate publication on acceptance

- Inclusion in PubMed, CAS, Scopus and Google Scholar

- Research which is freely available for redistribution 